\title{
Structural and Electrical Properties of an Electrolyte-insulator-metal Device with Variations in the Surface Area of the Anodic Aluminum Oxide Template for $\mathbf{p H}$ Sensors
}

\author{
Yong-Jun Kim*, Sung-Gap Lee ${ }^{\dagger}$, Jin-Ho Yeo* and Ye-Won Jo*
}

\begin{abstract}
In this study, we fabricated an electrolyte-insulator-metal (EIM) device incorporating a high- $\mathrm{k}_{2} \mathrm{O}_{3}$ sensing membrane using a porous anodic aluminum oxide (AAO) through a two-step anodizing process for $\mathrm{pH}$ detection. The structural properties were observed by field-emission scanning electron microscopy (FE-SEM) and X-ray diffraction patterns (XRD). Electrochemical measurements taken consisted of capacitance-voltage $(\mathrm{C}-\mathrm{V})$, hysteresis voltage and drift rates. The average pore diameter and depth of the AAO membrane with a pore-widening time of 20 min were $123 \mathrm{~nm}$ and $273.5 \mathrm{~nm}$, respectively. At a pore-widening time of $20 \mathrm{~min}$, the EIM device using anodic aluminum oxide exhibited a high sensitivity $(56 \mathrm{mV} / \mathrm{pH})$, hysteresis voltage $(6.2 \mathrm{mV})$ and drift rate $(0.25 \mathrm{mV} / \mathrm{pH})$.
\end{abstract}

Keywords: Nanostructures, Electrochemical properties

\section{Introduction}

An ion-sensitive field effect transistor (ISFET) is an electrochemical sensor that reacts to ionic activity at the electrolyte/membrane interface of an exposed gate window [1]. When using sensing membranes such as $\mathrm{Si}_{3} \mathrm{~N}_{4}, \mathrm{Al}_{2} \mathrm{O}_{3}$, $\mathrm{Ta}_{2} \mathrm{O}_{5}$, and $\mathrm{Sm}_{2} \mathrm{O}_{3}$, the ISFETs display near-Nernstian $\mathrm{pH}$ sensitivities. However, ISFET devices have some crucial drawbacks, such as poor adhesion and fast leaching-out of sensitive materials, as well as electrochemical corrosion of the passivation layer, and high fabrication costs due to the photolithographical process steps [2]. In contrast, capacitive electrolyte-insulator-silicon (EIS) is easy to manufacture and measure its characteristics, but is difficult to miniaturize, affecting the surface area of the sensor. In order to solve these problems, studies on changing the surface area have been conducted [3, 4]. However, ISFET and EIS devices have some disadvantages, such as drift, hysteresis and photosensitivity [5], which lower the accuracy of the sensor. High-k (high-dielectric constant) membranes can be considered as sensing membranes for application in ISFET and EIS devices. In general, high-k dielectrics, such as $\mathrm{Ta}_{2} \mathrm{O}_{5}, \mathrm{HfO}_{2}$, and $\mathrm{Al}_{2} \mathrm{O}_{3}[6,7]$, need to be thermally and chemically stable. In addition, they are required to have a large dielectric constant, small leakage current, and good interface quality [8].

In this study, we fabricated an electrolyte-insulator-metal (EIM) device using a porous anodic aluminum oxide (AAO) sensing membrane [9-11], which easily provides a

$\dagger$ Corresponding Author: Dept. of Ceramic Engineering, RIGET, Gyeongsang National University, Korea. (lsgap@gnu.ac.kr)

* Dept. of Ceramic Engineering, RIGET, Gyeongsang National

University, Korea. (\{81raykim, jhyeo1989, jos3372\}@gmail.com)

Received: February 17, 2015; Accepted: September 14, 2015

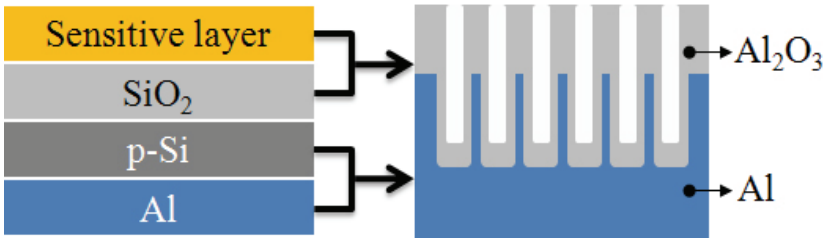

(a)

(b)

Fig. 1. Schematic diagram of (a) EIS device and (b) EIM device.

large surface area and improves sensitivity and stability. Fig. 1 shows a cross-sectional illustration of the EIS device and EIM device. In order to use EIS devices as electrochemical sensors, we should prepare metal electrodes at the bottom of the semiconductor part. On the other hand, the EIM structure can use the metal substrate directly as an electrode.

\section{Experimental}

High-purity aluminum foil $(99.9995 \%$, annealed, Alfa Aeser) specimens of $1 \times 1 \mathrm{~cm}^{2}$ with a thickness of $0.5 \mathrm{~mm}$ were used as the substrate. Prior to anodization, the metal surfaces were degreased in ethyl alcohol for $30 \mathrm{~min}$. They were electropolished in a solution of perchloric acid and ethyl alcohol $(1: 4$ volumetric ratio) at $15 \mathrm{~V}$ with 100 $\mathrm{mA} / \mathrm{cm}^{2}$, and $10^{\circ} \mathrm{C}$ for $3 \mathrm{~min}$. After electropolishing, the first step of the anodizing process was carried out in $0.04 \mathrm{M}$ oxalic acid $\left(\mathrm{H}_{2} \mathrm{C}_{2} \mathrm{O}_{4}\right)$ at $10^{\circ} \mathrm{C}, 80 \mathrm{~V}$ for $1 \mathrm{~h}$. The AAO membrane was then removed by immersing the specimen in a mixture of $1.8 \mathrm{wt} \%$ chromic acid $\left(\mathrm{H}_{2} \mathrm{CrO}_{4}\right)$ and $6 \mathrm{wt} \%$ phosphoric acid $\left(\mathrm{H}_{3} \mathrm{PO}_{4}\right)$ at $65^{\circ} \mathrm{C}$ for $2 \mathrm{~h}$. Then, porous-type 
AAO films were obtained by carrying out the second anodizing step in an oxalic acid solution for $3 \mathrm{~min}$. After the second anodizing step, the pores were widened by etching in a $5 \mathrm{wt} \%$ phosphoric acid solution at $45^{\circ} \mathrm{C}$ for 0 20 min.

The structure of the AAO substrate was analyzed by Xray diffraction (XRD) with $\mathrm{CuK}_{a}$ emission. The surface and cross-sectional microstructures of the AAO membrane were examined using field-emission scanning electron microscopy (FE-SEM). The $\mathrm{pH}$ sensitivities of the EIM devices were determined by measuring the capacitancevoltage $(\mathrm{C}-\mathrm{V})$ curves. In order to measure the $\mathrm{C}-\mathrm{V}$ characteristics, specimens were mounted in a home-made measuring cell sealed by an O-ring. The front side of the specimen was in contact with the electrolyte and an $\mathrm{Ag} / \mathrm{AgCl}$ reference electrode (011464, BAS Inc.), and on the rear side with a gold-plated pin. An LCR meter (PM6306, Fluke) was operated at an ac signal magnitude of $50 \mathrm{mV}$ and frequency of $120 \mathrm{~Hz}$, and technical buffer solutions (Titrisol, Merck) of $\mathrm{pH}$ 3-11 were used. Hysteresis voltage and drift rate were measured using a voltage meter (Keithley 6517A).

\section{Results and Discussion}

Fig. 2 shows the XRD pattern of the anodic aluminum oxide membrane. The anodic aluminum oxide membrane showed the typical XRD pattern of a polycrystalline structure with the $\gamma-\left(\mathrm{Al}_{2} \mathrm{O}_{3}\right)_{1.333}$ phase. This was confirmed by JCPDS card; 01-075-0921.

Fig. 3 and Fig. 4 show the surface and cross-sectional FE-SEM micrographs of AAO membranes by porewidening time. By increasing the pore-widening time from $0 \mathrm{~min}$ to $25 \mathrm{~min}$ (Fig. 3(a) and 3(d)), the average pore diameter increased from $63 \mathrm{~nm}$ to $158 \mathrm{~nm}$. However, the AAO membranes pore-widened for $25 \mathrm{~min}$ broke due to excessive etching. In the cross sectional FE-SEM micrographs of the AAO (Fig. 4), the upper parts of the AAO membrane were wider than the bottom portion. We expected these microstructures to display excellent

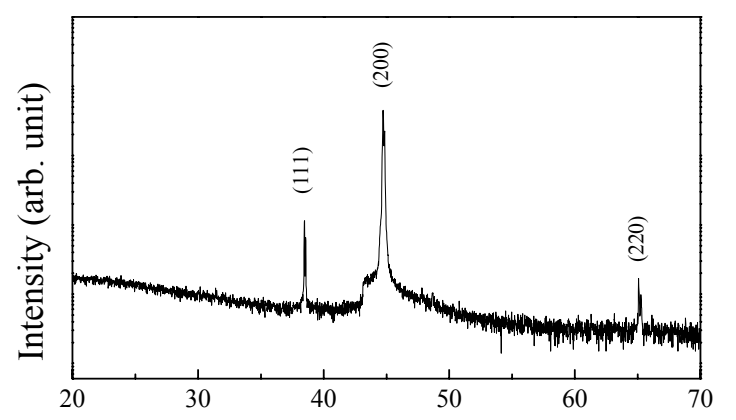

Diffraction degrees (20)

Fig. 2. XRD pattern of the anodic aluminum oxide membrane.

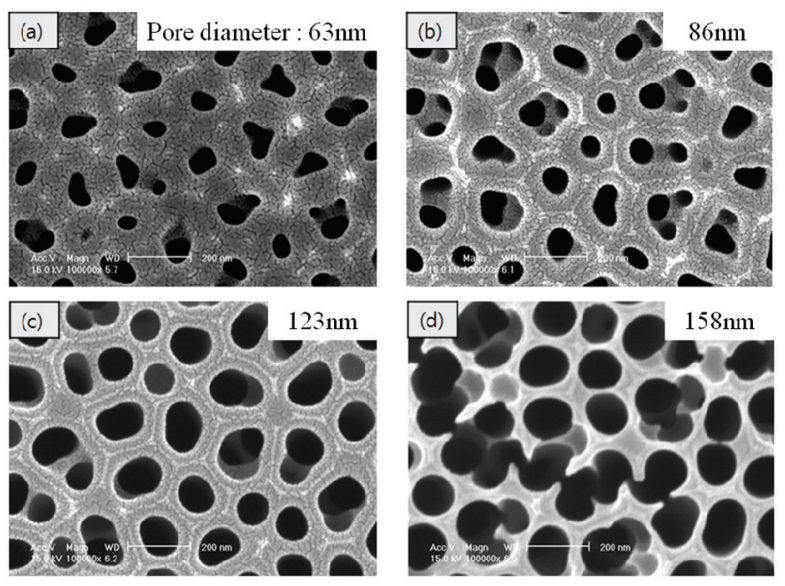

Fig. 3. Surface FE-SEM micrographs of AAO porewidened for : (a) $0 \mathrm{~min}$, (b) $10 \mathrm{~min}$, (c) $20 \mathrm{~min}$ and (d) $25 \mathrm{~min}$.
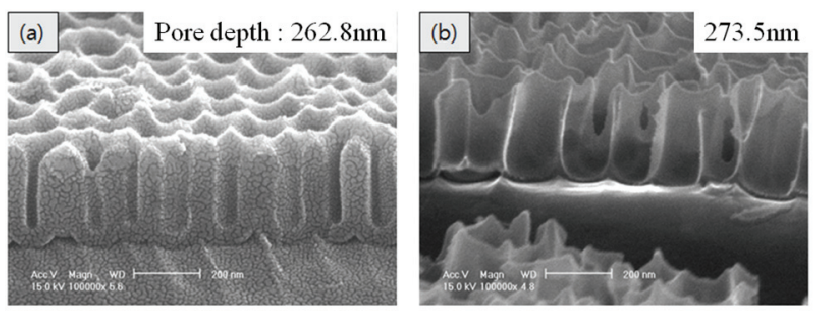

Fig. 4. Cross-sectional FE-SEM micrographs of AAO porewidened for: (a) $0 \mathrm{~min}$, and (b) $20 \mathrm{~min}$.

characteristics to detect liquid materials, due to the increase of the entrance and contact area. The thickness of the whole side of the $\mathrm{Al}_{2} \mathrm{O}_{3}$ layer decreased during the porewidening process. The average pore diameter and depth of the AAO membrane with a pore-widening time of $20 \mathrm{~min}$ were $123 \mathrm{~nm}$ and $273.5 \mathrm{~nm}$, respectively.

Fig. 5 shows $\mathrm{C}-\mathrm{V}$ curves for the EIS devices in different $\mathrm{pH}$ buffer solutions. The $\mathrm{C}-\mathrm{V}$ curves were measured to determine the $\mathrm{pH}$ sensitivities of the sensing membrane. Varying the $\mathrm{pH}$ solution leads to the flat band voltage shift in the $\mathrm{C}-\mathrm{V}$ curves. This behavior can be explained by considering the site-binding model [12]. The reference voltage was determined from the $\mathrm{C}-\mathrm{V}$ curves to achieve the normalized capacitance of 0.5 . The $\mathrm{C}-\mathrm{V}$ curves shifted as a result of the surface potential modification by hydrogen ions. The AAO membrane with the pore-widening time of $20 \mathrm{~min}$ showed the highest sensitivity value of $56 \mathrm{mV} / \mathrm{pH}$, as shown in Fig. 5(f). The $\mathrm{pH}$ sensitivity increased with an increase in the surface area of the AAO membrane due to the increasing capacitance value of the measuring signal [13].

Fig. 6 shows the hysteresis behavior of AAO sensors at various pore-widening times. Hysteresis behavior was measured by immersing the prepared sensors in each $\mathrm{pH}$ standard solution for up to $5 \mathrm{~min}$ in a set cycle of $\mathrm{pH}$ $7 \rightarrow 11 \rightarrow 7 \rightarrow 3 \rightarrow 7$. Despite an improvement in $\mathrm{pH}$ 
(a)

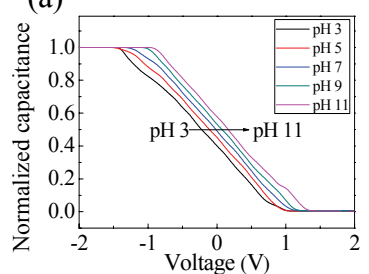

(c)

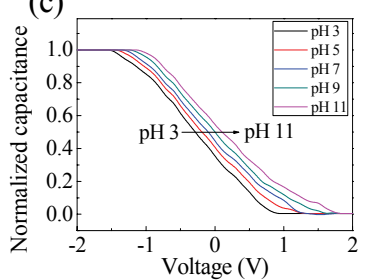

(e)

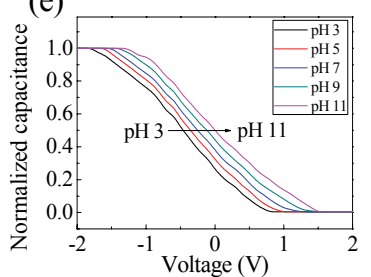

(b)

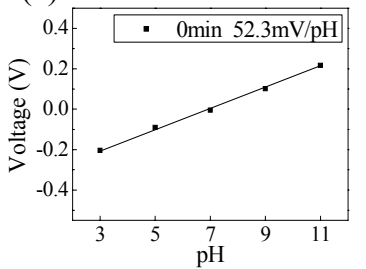

(d)

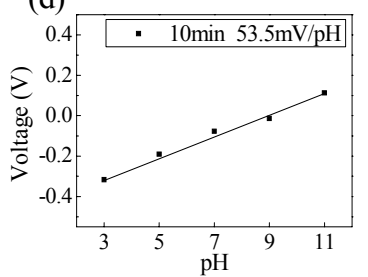

(f)

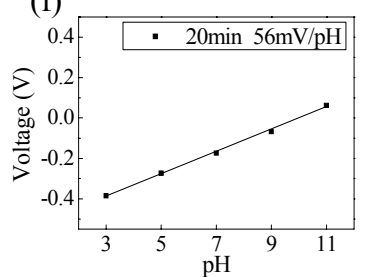

Fig. 5. Normalized $\mathrm{C}-\mathrm{V}$ curves response of AAO membrane different $\mathrm{pH}$ buffer solutions, and $\mathrm{pH}$ sensitivity of the AAO membrane: pore-widening time (a), (b) 0min; (c), (d) $10 \mathrm{~min}$; (e), (f) $20 \mathrm{~min}$.

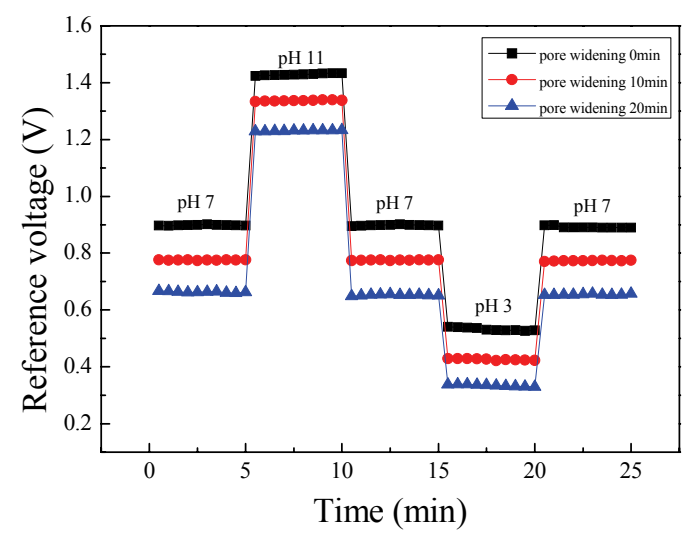

Fig. 6. Hysteresis voltage of AAO membrane at various pore-widening times

sensitivity, the hysteresis properties of the AAO membrane worsened slightly with an increase in pore-widening time. Hysteresis can be explained by defects in the insulator film. These responding sites respond to changes in the chemical composition of the solution in which the device is immersed, even though they are not located on the outer surface of the insulator. The responding site is located along the boundaries of grains on the insulator film [14].

Fig. 7 shows drift properties of AAO membranes at various pore-widening times at $\mathrm{pH}$ 7. The drift rate in the reference voltage of the EIS over a long time period poses a serious challenge in the widespread application of the

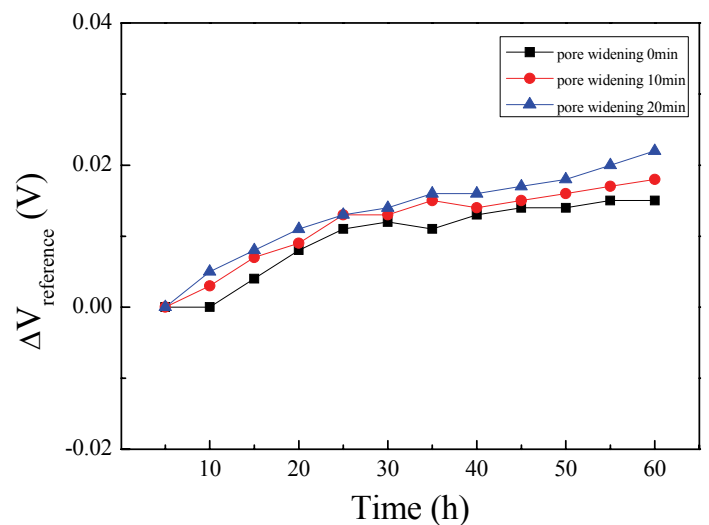

Fig. 7. Drift rates of AAO membranes at various porewidening times at $\mathrm{pH} 7$.

Table. 1. Sensitivity, Hysteresis voltage, and Drift rates of AAO membranes at various pore-widening times.

\begin{tabular}{c|c|c|c}
\hline $\begin{array}{c}\text { Pore widening time } \\
(\mathrm{min})\end{array}$ & $\begin{array}{c}\text { Sensitivity } \\
(\mathrm{mV} / \mathrm{pH})\end{array}$ & $\begin{array}{c}\text { Hysteresis voltage } \\
(\mathrm{mV})\end{array}$ & $\begin{array}{c}\text { Drift rate } \\
(\mathrm{mV} / \mathrm{h})\end{array}$ \\
\hline $0 \mathrm{~min}$ & 52.3 & 6.2 & 0.34 \\
\hline $10 \mathrm{~min}$ & 53.5 & 6.5 & 0.29 \\
\hline $20 \mathrm{~min}$ & 56 & 6.8 & 0.25 \\
\hline
\end{tabular}

solid-state $\mathrm{pH}$ sensor $[15,16]$. Drift is known to increase slowly and monotonically with time when sensors are submerged in an electrolyte. Consequently, a higher drift rate is considered to be caused by a larger surface roughness, which indicates an increase in the possibility of the presence of defects in the dielectric material.

\section{Conclusion}

We fabricated an AAO nano template using a two-step anodizing process. In addition, the sensing properties of hydrogen ions were investigated at various pore-widening times. The structure of the AAO substrate was analyzed by X-ray diffraction (XRD) with $\mathrm{CuK}_{\alpha}$ emission and using field-emission scanning electron microscopy (FE-SEM). By increasing the pore-widening time from $0 \mathrm{~min}$ to 20 min (Fig. 3(a) and 3(c)), average pore diameter increased from $63 \mathrm{~nm}$ to $158 \mathrm{~nm}$. The AAO membranes pore-widened for longer than $25 \mathrm{~min}$ broke due to excessive etching. The $\mathrm{pH}$ sensitivity, hysteresis voltage and drift rate of an EIM device at the pore-widening time of $20 \mathrm{~min}$ were $56 \mathrm{mV} / \mathrm{pH}$, $6.2 \mathrm{mV}$ and $0.25 \mathrm{mV} / \mathrm{pH}$, respectively.

\section{Acknowledgements}

This research was supported by the Pioneer Research Center Program through the National Research Foundation of Korea funded by the Ministry of Education, Science and Technology (2011-0001704). 


\section{References}

[1] P. Bergveld, IEEE Trans. Biomed. Eng., vol. BME-17, pp. 70-71, 1970.

[2] Lee. C. S., Kim. S. K., and M. I., Sensors, vol. 9, pp. 7111-7131, 2009.

[3] M. J. Schöning, Sensors and Actuators B, vol. 65, pp. 288-290, 2000.

[4] C. D. Fung, IEEE Trans. Electron Dev., vol. 33, pp. 8-18, 1986.

[5] P. V. Bobrov, Sensors and Actuators B, vol. 3, pp. 7581, 1991.

[6] C. S. Lai, Solid state lett., vol. 9, pp. 90-92, 2006.

[7] S. Yoshida, J. Electrochem. Soc., vol. 151, pp. 53-58, 2004.

[8] T. M Pan, Sensors and Actuators B, vol. 138, pp. 619-624, 2009.

[9] H. Masuda, H. Yamada, Masahiro and H. Asoh, Applied Physics Letters, vol. 71, pp. 2770-2772, 1997.

[10] H. Masuda, A. Yotsuya, M. Asano, K. Nishio, M. Nako, A. Yokoo, T. Tamamura, Applid Physics Letters, vol.78, pp.826-828, 2001.

[11] C. C. Chen, J. H. Chen, C. G. Chao, Japanese Journal of Applied Physics, vol. 44, pp. 1529-1533, 2005.

[12] D. L. Harame, L. J. Bousse, J. D. Shott, J. D. Meindl, IEEE Trans. Electron Devices, vol. 34, pp. 1700-1707, 1987.

[13] M.J. Schöning, F. Ronkel, M. Crott, M. Thust, J.W. Schultze, P. Kordos, H. Lüth, Electrochimica Acta, vol. 42, pp. 3185-3193, 1997.

[14] L. Bousse, Sensors and Actuators B, vol. 2, pp. 103110, 1990.

[15] T. M. Pan, Sensors and Actuators B, vol. 144, pp. 139-145, 2010.

[16] M. S. Islam, Sensors and Actuators B, vol. 171-172, pp. 238-243, 2012.

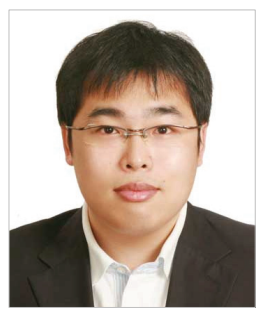

Yong-Jun Kim received his B.S. degree in Electronics Engineering from Konkuk University, Korea, in 2012 and M.S. degree in Materials Engineering and Convergence Technology from Gyeongsang National University, Korea, in 2014, respectively. His research interests include nanotube, and appli-

cation of biosensor

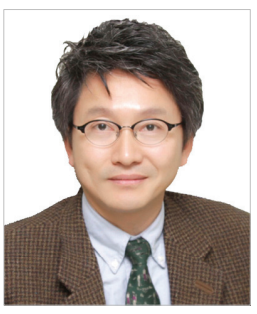

Sung-Gap Lee received his M.S. and Ph.D. degrees from the Department of Electronic Materials Engineering from Kwangwoon University. He is currently a professor with the Dept. of Ceramic Engineering from Gyeongsang National University. His main research themes are ceramic sensor and ferroelectric

ceramic thin films

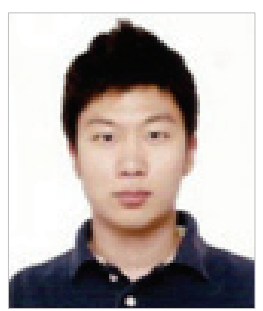

Jin-Ho Yeo received his B.S. degree in Ceramic Engineering from Gyeongsang National University, Korea, in 2013 and M.S. degree in nano Materials Engineering and Convergence Technology from Gyeongsang National University, Korea, in 2015, respectively. His research interests include nano structure, and application of biosensor.

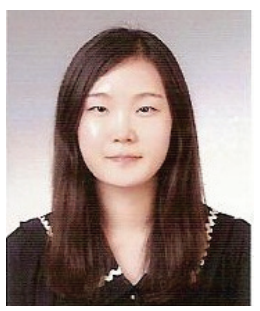

Ye-Won Jo received her B.S. degree in Ceramic Engineering from Gyeongsang National University, Korea, in 2014. Currently, she is M.S. degree in nano Materials Engineering and Convergence Technology from Gyeongsang National University, Korea. Her research interests include nano structure, and application of chemical sensor. 